\title{
Hubungan Pengetahuan Kebugaran Jasmani dengan Tingkat Kebugaran Jasmani
}

\author{
The Relationship between Physical Fitness Knowledge \\ and Physical Fitness Level
}

\author{
Rama Adha Septiana \\ STKIP Pasundan, Cimahi, Jawa Barat, Indonesia \\ Ramaadha7@gmail.com
}

\begin{abstract}
Abstrak
Tujuan dari penelitian ini untuk mengetahui apakah ada hubungan pengetahuan kebugaran jasmani dengan tingkat kebugaran jasmani. Penelitian ini menggunakan metode kuantitatif dengan desain penelitian korelasional. Populasi dalam penelitian ini adalah siswa SMPN 3 Ciparay, sampel yang diambil adalah siswa kelas IX A sebanyak 36 orang. Penelitian ini dilaksanakan 1 kali pertemuan. Instrumen yang digunakan yaitu Angket Pengetahuan Kebugaran Jasmani dan Tes Kebugaran Jasmani Indonesia (TKJI). Berdasarkan dari hasil pengolahan dan analisis data hasil pembahasan penelitian dan analisis data-data dari hasil penelitian yang terkumpul, maka dapat diambil kesimpulan sebagai berikut: Mencari rata-rata hasil Tes Angket Pengetahuan Kebugaran Jasmani adalah 15 dan simpangan baku 1,6 dengan persentase 11\% baik. 83\% Cukup Bagus dan 6\% kurang sedangkan hasil Tes Kebugaran Jasmani Indonesia (TKJI) rata - rata 16,06 dan simpangan baku 1,79 dengan persentase kurang 6\% sedang 64\% dan baik $31 \%$. Sehingga dapat diketahui bahwa mayoritas siswa memiliki hasil angket kebugaran jasmani cukup bagus $83 \%$ dan hasil tes kebugaran jasmani Indonesia sedang $64 \%$.
\end{abstract}

Kata Kunci : Pengetahuan Kebugaran jasmani dan Tingkat Kebugaran Jasmani.

\begin{abstract}
The purpose of this study was to determine whether there was a relationship between physical fitness knowledge and physical fitness level. This study uses quantitative methods with correlational research designs. The population in this study were students of Ciparay Junior High School 3, the sample taken was 36 A grade students of 36 people. This research was conducted in one meeting. The instruments used were the Physical Fitness Knowledge Questionnaire and the Indonesian Physical Fitness Test (TKJI). Based on the results of data processing and analysis of the results of the discussion of research and analysis of data from the results of the collected research, it can be concluded as follows: Finding the average results of the Physical Fitness Knowledge Questionnaire Test is 15 and the standard deviation is 1.6 with a percentage of $11 \%$ well. $83 \%$ is pretty good and $6 \%$ less while the results of the Indonesian Physical Fitness Test (TKJI) are on average 16.06 and standard deviation is 1.79 with a percentage of less than $6 \%$ being $64 \%$ and good $31 \%$. So that it can be seen that the majority of students have a good physical fitness questionnaire $83 \%$ and the results of the Indonesian physical fitness test are $64 \%$.
\end{abstract}

Keywords: Physical Fitness Knowledge and Physical Fitness Level. 


\section{PENDAHULUAN}

Pendidikan jasmani memiliki peran yang sangat penting dalam mengintensifkan penyelenggaraan pendidikan sebagai suatu proses pembinaan manusia yang berlangsung seumur hidup. Pendidikan jasmani memberi kesempatan untuk terlibat langsung dalam aneka pengalaman belajar melalui aktivitas jasmani, bermain, dan berolahraga yang dilakukan secara sistematis, terarah dan terencana (Hughson \& Tapsell, 2012; Lynch \& Soukup, 2016; Sallis \& McKenzie, 2013). Pembekalan pengalaman belajar itu diarahkan untuk membina, sekaligus membentuk gaya hidup sehat dan aktif sepanjang hayat. Selain itu pendidikan jasmani juga mempunyai manfaat yaitu memenuhi kebutuhan gerak, mengenalkan lingkungan dan potensi dirinya, menanamkan dasar-dasar keterampilan yang berguna, menyalurkan energi yang berlebihan dan merupakan proses pendidikan secara serempak baik fisik mental maupun emosional. Kesehatan adalah hal yang utama untuk melakukan semua aktivitas. Jika seseorang memiliki kesehatan yang baik maka akan sangat mudah sekali untuk melalukan apa yang diinginkan. Kesehatan dan pendidikan adalah hal yang berkaitan.

Dalam perkembangan pendidikan jasmani dan pendidikan kesehatan sangat erat hubungannya karena perkembangan jasmani seorang anak akan tumbuh baik jika didukung oleh pengetahuan kesehatan yang baik. Misalnya pengetahuan tentang hidup sehat dan pola makan yang sehat akan mempengaruhi pertumbuhan dan perkembangan fisik maupun psikis anak (Rochman, 2016). Melalui pendidikan jasmani olahraga dan kesehatan siswa akan mempunyai pengetahuan tentang pentingnya kebugaran jasmani, disamping itu juga akan mengembangkan kemampuan kondisi fisik siswa agar lebih baik, sehingga siswa akan mempunyai daya tahan yang bagus, serta melatih kecepatan dan kelincahan siswa dalam melakukan aktivitas fisik. Dalam melakukan aktivitas sehari-hari manusia sebagai makhluk hidup membutuhkan kondisi tubuh yang bugar karena apabila seseorang memiliki tubuh yang bugar suatu pekerjaan akan didapat dengan hasil yang maksimal. Kebugaran jasmani sangat diperlukan oleh manusia, maka dari itu kebugaran jasmani yang berkaitan dengan diri seseorang siswa merupakan aspek penting yang harus di jaga.

Untuk mempertahankan kebugarannya, siswa dituntut untuk mengatur pola hidupnya dengan teratur berolahraga atau menghindari makanan yang tidak sesuai dengan tubuhnya, dengan begitu siswa akan memiliki tingkat kebugaran jasmani yang ingin dimilikinya sehingga dapat memaksimalkan pikiran dan tenaganya untuk beraktivitas disekolah.

Kebugaran jasmani (KJ) merupakan derajat sehat dinamis seseorang yang menjadi kemampuan jasmani dasar untuk dapat melaksanakan tugas yang harus dilaksanakan (Giriwijoyo \& Zafarsidiq, 2012). Kebugaran jasmani pada umumnya dipengaruhi oleh dua faktor yaitu faktor internal dan faktor eksternal. Faktor internal adalah sesuatu yang sudah terdapat dalam tubuh 
seseorang yang bersifat menetap misalnya genetik, umur, dan jenis kelamin. Faktor eksternal adalah faktor dari luar diantaranya gizi, merokok, istirahat, tidur, serta olahraga. Faktor lain yang juga dapat mempengaruhi tingkat kebugaran jasmani seseorang yaitu pengetahuan dan sikap individu tersebut terhadap kebugaran jasmani itu sendiri. Pengetahuan adalah fakta dan keadaan atau kondisi yang dimengerti setelah sesorang melakukan penginderaan terhadap kebugaran jasmani.

Bentuk perilaku terhadap respon ini dapat bersifat pasif tanpa tindakan dan dapat bersifat aktif jika dengan tindakan. Pengetahuan sangat berpengaruh terhadap terbentuknya perilaku seseorang terhadap kebugaran jasmani. Berdasarkan penelitian dari Tompson \& Hannon (2012) yang mengemukakan terdapat hubungan antara pengetahuan tentang kebugaran dengan frekuensi aktifitas fisik. Bahwa semakin tinggi pengetahuan tentang kebugaran jasmani seseorang maka semakin tinggi frekuensi aktifitas fisiknya, sehingga dengan tingginya pengetahuan dapat mempengaruhi tingkat kebugaran.jasmani individu tersebut.

Dalam proses pembelajaran pendidikan jasmani guru harus dapat mengajarkan berbagai keterampilan gerak dasar, teknik dan strategi permainan/olahraga, internalisasi nilainilai (sportifitas, jujur, kerjasama, dan lain-lain) dari pembiasaan pola hidup sehat. Pelaksanaannya bukan melalui pengajaran konvensional di dalam kelas yang bersifat kajian teoritis, namun melibatkan unsur fisik mental, intelektual, emosional dan sosial.

Aktivitas yang diberikan dalam pengajaran harus mendapatkan sentuhan didakdik metodik, sehingga aktivitas yang dilakukan dapat mencapai tujuan pengajaran. Melalui pendidikan jasmani diharapkan siswa dapat memperoleh berbagai pengalaman untuk mengungkapkan kesan pribadi yang menyenangkan, kreatif, inovatif, terampil, meningkatkan dan memelihara kesegaran jasmani serta pemahaman terhadap gerak manusia. Adanya ruang lingkup mata pelajaran pendidikan jasmani untuk jenjang SD/MI, SMP/MTs, dan SMA/MA sebenarnya sangat membantu pengajar pendidikan jasmani dalam mempersiapkan, melaksanakan dan mengevaluasi kegiatan siswa.

Adapun ruang lingkup pendidikan jasmani meliputi aspek permainan dan olahraga, aktivitas pengembangan, uji diri/ senam, aktivitas ritmik, akuatik (aktivitas air) dan pendidikan luar kelas. Oleh karena itu, program pendidikan jasmani, kesehatan dan olahraga diharapkan mampu memberikan sumbangan terhadap proses pertumbuhan dan perkembangan anak. Di SMPN 3 Ciparay Kabupaten Bandung belum pernah dilaksanakantes kebugaran jasmani, sehingga menjadi masalah yang harus dicari solusi atau pemecahannya, agar siswa bugar dan pelaksanaan pembelajaran dapat berjalan lancar. Jika hanya mengandalkan program pendidikan jasmani yang dilaksanakan di sekolah maka peningkatan kesegaran jasmani siswa tentu tidak 
akan tercapai, karena kesegaran jasmani merupakan tanggung jawab orangtua wali murid dan sekolah. Di samping itu, pelajaran pendidikan jasmani olahraga dan kesehatan Di SMPN 3 Ciparay Kabupaten Bandung diberikan hanya satu kali dalam seminggu, sehingga kurang dapat meningkatkan kesegaran jasmani siswa. Di SMPN 3 Ciparay Kabupaten Bandung juga ditemukan permasalahan yang belum pernah diteliti atau diselidiki oleh siapapun. Masalah yang saya angkat dalam penelitian ini adalah adanya siswa yang berprestasi dalam bidang olahraga tetapi kebugaran jasmaninya kurang baik. Oleh karena itu perlu diadakan penelitian agar permasalahan dapat terpecahkan. Berdasarkan uraian di atas, diketahui bahwa belum pernah dilakukan pemantauan terhadap tingkat kebugaan jasmani siswa SMPN 3 Ciparay Kabupaten Bandung, sehingga peneliti bermaksud mengadakan penelitian untuk mengetahui seberapa besar hubungan pengetahuan kebugaran jasmani dengan tingkat kebugaran jasmani siswa SMPN 3 Ciparay Kabupaten Bandung.

\section{METODE}

Metode yang digunakan dalam penelitian ini adalah kuantitatif, Penelitian ini menggunakan pendekatan korelasional, dalam penelitian kuantitatif pendekatan korealasional adalah suatu pendekatan umum dengan tujuan untuk mengetahui hubungan antara dua variabel atau lebih, atau hubungan antara variabel bebas dengan variabel terikat (Sugiyono, 2007). Dalam penelitian ini terdapat dua variabel yaitu Pengetahuan Kebugaran Jasmani (X), disebut variabel bebas, dan Kebugaran Jasmani (Y) yang disebut variabel terikat.

Adapun populasi dalam penelitian ini adalah seluruh siswa di SMPN 3 Ciparay Kabupaten Bandung. Pemilihan sampel dikakukan melalui teknik cluster random sampling (Fraenkel et al., 2012), dan terpilih kelas IX A yang memiliki jumlah siswa sebanyak 36 orang sebagai sampel.

Sementara itu instrumen yang digunakan dalam penelitian ini yaitu instrumen angket untuk mengetahui sejauh mana tingkat pengetahuan kebugaran jasmani siswa dan instrumen TKJI (Nurhasan, 2012) untuk mengetahui tigkat kebugaran jasmaninya. Kemudian data yang diperoleh diolah mnggunakan aplikasi SPSS versi 21.

\section{HASIL DAN PEMBAHASAN}

\section{Hasil}

Hasil tes dari tiap-tiap butir tes kemudian dikonversi menjadi nilai dengan menggunakan tabel angket persepsi siswa. 
Tabel 1. Deskripsi Pengetahuan Kebugaran Jasmani

\begin{tabular}{|c|c|c|c|c|}
\hline No & Interval & Kategori & $\mathbf{F}$ & $\%$ \\
\hline 1 & $27-23$ & Sangat Bagus & 0 & $0 \%$ \\
\hline 2 & $22-18$ & Bagus & 4 & $11 \%$ \\
\hline 3 & $17-13$ & Cukup & 30 & $83 \%$ \\
\hline 4 & $12-8$ & Kurang & 2 & $6 \%$ \\
\hline 5 & $7-0$ & Kurang Sekali & 0 & $0 \%$ \\
\hline \multicolumn{3}{|c|}{ Jumlah } & 36 & $100 \%$ \\
\hline
\end{tabular}

Berdasarkan Tabel di atas dapat dijelaskan bahwa Pengetahuan Kebugaran Jasmani siswa SMPN 3 Ciparay 11\% baik. 83\% Cukup Bagus dan 6\% kurang. Sedangkan diperoleh rata rata 15 (lihat Tabel 4.2) yang terletak pada interval ke-3 (interval 17-13) dalam kategori "Cukup Bagus", dan simpangan baku 1,6 menunjukan Pengetahuan Kebugaran Jasmani seluruh siswa cukup.

Data variabel tingkat kebugaran jasmani ditentukan berdasarkan norma Tes Kebugaran Jasmani Indonesia.

Tabel 2. Hasil Tes Kebugaran Jasmani

\begin{tabular}{|c|c|c|c|c|}
\hline No & Nilai & Klasifikasi & F & $\%$ \\
\hline 1 & $5-9$ & Kurang Sekali & 0 & $0 \%$ \\
\hline 2 & $10-13$ & Kurang & 2 & $6 \%$ \\
\hline 3 & $14-17$ & Cukup & 23 & $64 \%$ \\
\hline 4 & $18-21$ & Baik & 11 & $31 \%$ \\
\hline 5 & $22-25$ & Baik Sekali & 0 & $0 \%$ \\
\hline \multicolumn{2}{|c|}{ Jumlah } & 36 & $100 \%$ \\
\hline
\end{tabular}

\section{Uji Normalitas dan Regresi Linear Variabel X ke Y}

Uji normalitas dilakukan untuk mengetahui normal tidaknya sebaran skor variabel pengetahuan kebugaran jasmani terhadap TKJI. Data dari variabel penelitian diuji normalitas sebarannya dengan menggunakan program SPSS Versi 21 (StatisticalPackage for Social Science) yaitu dengan uji Chi-Square. Kaidah yang digunakan untuk menguji normalitas adalah jika nilai signifikansi $\mathrm{p}>0,05$ maka distribusi data tersebut normal, dan jika nilai signifikansi $\mathrm{p}<0,05$ maka distribusi data tersebut tidak normal.

\section{Tabel 3. Uji Normalitas}

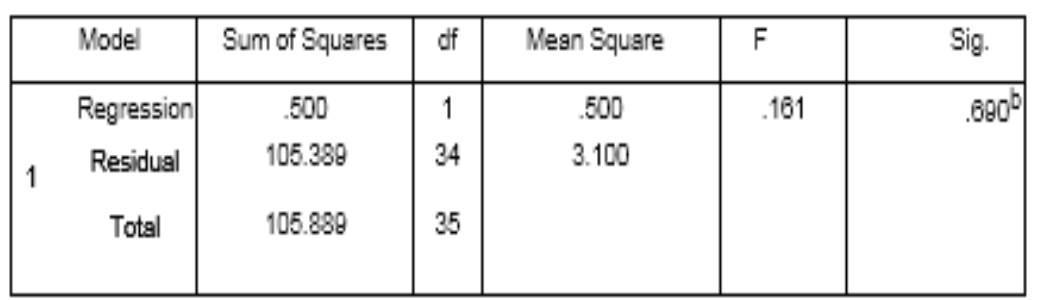


Dari di atas dapat dilihat bahwa nilai signifikansi variabel TKJI adalah 0,690>0,05. Sesuai kaidah yang ditentukan, bila nilai signifikansi p> 0,05 maka distribusi data tersebut normal.

Analisis uji linieritas dalam penelitian ini menggunakan uji linieritas dari program SPSS versi 21. Penggunaan Uji Linieritas Hubungan untuk memastikan apakah derajat hubungannya. Kaidah yang digunakan untuk menguji linieritas hubungan adalah: Jika signifikansi $\mathrm{p}<0,05$, maka hubungannya adalah linier, sebaliknya jika signifikansi $\mathrm{p}>0,05$, maka hubungannya adalah tidak linier.

\section{Tabel 4. Hasil Uji Linieritas Pengetahuan Kebugaran Jasmani Terhadap TKJI}

\begin{tabular}{|c|c|c|c|c|}
\hline Model & $\mathrm{R}$ & $\mathrm{R}$ Square & $\begin{array}{c}\text { Adjusted R } \\
\text { Square }\end{array}$ & Std. Error of the Estimate \\
1 & $.069^{\mathrm{a}}$ & .005 & -.025 & 1.761 \\
\hline
\end{tabular}

Berdasarkan uji linieritas hubungan dengan menggunakan bantuan SPSS diperoleh nilai $\mathrm{R}$ Square $=0,005$ dengan $\mathrm{F}=0,161$ dan signifikansi $=0,690>0,05$, maka dapat diartikan hubungannya adalah Tidak linier. Hasil penelitian menunjukkan tidak adanya hubungan yang signifikan antara Pengetahuan Kebugaran Jasmani dengan Tingkat Kebugaran Jasmani SiswaSiswi kelas IX SMPN 3 Ciparay Tahun Pelajaran 2017/2018.

\section{Pembahasan}

Hasil pada penelitian di atas mengemukakan bahwa anak yang memiliki pengetahuan kebugaran jasmani yang sangat baik, tidak menjamin bahwa ia memiliki tingkat kebugaran jasmani yang baik pula. Begitupun sebaliknya, anak yang memiliki pengetahuan tentang kebugaran jasmani yang kurang, tidak menjamin bahwa anak itu memiliki kebugaran jasmani yang buruk. Tinggi-rendahnya atau baik-buruknya tingkat kebugaran jasmani seseorang tidak serta-merta ditentukan oleh pengetahuannya, melainkan oleh aktifitas-aktifitas gerak yang ia lakukan sehari-hari. Terkadang rasa malas dan rasa lelah menghambat seseorang yang memiliki pengetahuan akan pentingnya kebugaran jasmani untuk melakukan olahraga. Hal-hal seperti ini perlu ditindaklanjuti kedepannya, karena "physical fitness" tidak hanya sebatas untuk diketahui saja, melainkan harus dimiliki oleh setiap siswa melalui beragam aktifitas-aktifitas gerak berupa olahraga yang dikemas dalam mata pelajaran pendidikan jasmani. 


\section{KESIMPULAN}

Pengetahuan kebugaran jasmani siswa siswi SMPN 3 Ciparay cukup bagus dan merata hal ini terlihat dari hasil deskripstif data hasil angket penelitian. Dan tingkat kebugaran jasmani siswa siswi SMPN 3 Ciparay sedang hal ini terlihat dari Tes Kebugaran Jasmani Indonesia (TKJ).

Dari analisis korelasi dapat disimpulkan bahwa tidak terdapat hubungan pengetahuan kebugaran jasmani dengan tingkat kebugaran jasmani siswa siswi SMPN 3 Ciparay, hal ini terlihat dari penerimaan $\mathrm{H}_{0}$ (tidak terdapat hubungan ) dan penolakan $\mathrm{H}_{1}$ (terdapat hubungan) dalam uji hipotesa.

\section{DAFTAR PUSTAKA}

Fraenkel, et.all. (2012). How to Design and Evaluate Reserch in Education. USA: McGraw Hill. Inc.

Giriwijoyo, Santoso \& Zafarsidiq, Dikdik. (2012). Ilmu Faal Olahraga (Fisiologi Olahraga) Bandung: Remaja Rosdakarya, 2012.

Hughson, J., \& Tapsell, C. (2012). Physical Education and the "Two Cultures " Debate: Lessons from Dr. Leavis. Quest. https://doi.org/10.1080/00336297.2006.10491891

Lynch, T., \& Soukup, G. J. (2016). “Physical education ”, “ health and physical education ”, “ physical literacy " and " health literacy ": Global nomenclature confusion. Cogent Education, 1-22. https://doi.org/10.1080/2331186X.2016.1217820

Nurhasan. 2012. Tes Dan Pengukuran Dalam Pendidikan Jasmani. Cimahi : STKIP Pasundan.

Rochman, Moch. (2016). Kontribusi Status Gizi Terhadap Kemampuan Motorik Kasar Siswa Sekolah Dasar. Jurnal Kesehatan Olahraga Vol 4. Nomor 01 Edisi Maret Tahun 2016 halaman 77-84

Sallis, J. F., \& McKenzie, T. L. (2013). Physical Education's Role in Public Health. Research Quarterly for Exercise and Sport. https://doi.org/10.1080/02701367.1991.10608701

Sugiyono, Metode Penelitian Pendidikan (Pendekatan Kuantitatif, Kualitatif, dan R\&D. Bandung: Alfabeta, 2007), h.13.

Thompson, A \& Hannon, JC. (2012). Health-related fitness knowledge and physical activity of high school students. Sagamore Journals. 